\title{
Erratum to: Inferior vena cava filters: current best practices
}

\author{
Anita Rajasekhar ${ }^{1}$
}

Published online: 11 June 2015

(C) Springer Science+Business Media New York 2015

\section{Erratum to: J Thromb Thrombolysis (2015) 39:315-327 \\ DOI 10.1007/s11239-015-1187-5}

In the original publication, a reference was mistakenly omitted by the author during manuscript preparation. The reference should be cited after the statement "Internationally, US providers place far more IVCFs compared to
European providers by a staggering 25:1 IVCF placement ratio with no significant difference in annual VTE-related deaths [16-18]" on p. 316 of the April 2015 issue of The Journal of Thrombosis and Thrombolysis.

The missing reference is: Wang SL, Lloyd AJ (2013) Clinical review: inferior vena cava filters in the age of patient-centered outcomes. Ann Med 45:474-481.

The online version of the original article can be found under doi: $10.1007 / \mathrm{s} 11239-015-1187-5$.

Anita Rajasekhar

rajasa@medicine.ufl.edu

1 University of Florida College of Medicine, Health Science Center, PO Box 100278, Gainesville, FL 32610, USA 